Elsevier required licence: (C) <2018>. This manuscript version is made available under the CC-BY-NCND 4.0 license http://creativecommons.org/licenses/by-nc-nd/4.0/

The definitive publisher version is available online at

[https://www.sciencedirect.com/science/article/pii/S0140988318302147?via\%3Dihub] 


\title{
Re-analyzing the Economic Impact of a Global Bunker Emissions Charge
}

\author{
Yu SHENG ${ }^{\text {a }}$, Xunpeng SHI ${ }^{\mathrm{b}, \mathrm{c}, \mathrm{d}} *, \mathrm{Bin}_{\mathrm{SU}}^{\mathrm{d}}$ \\ a. School of Advanced Agricultural Sciences, Peking University. \\ b. University of Technology Sydney, Australian China Relations Institute, Ultimo 2007, \\ Australia. Email:xunpeng.shi@gmail.com \\ c. School of Low Carbon Economy, Hubei University of Economics, Wuhan, China. \\ d. Energy Studies Institute, National University of Singapore, Singapore 119620.
}

\section{[Abstract]}

Regulating bunker emissions continues to be a challenging task, largely due to the lack of a globally coordinated scheme providing economic and political incentives to potential participating countries. This paper analyses the economic costs and benefits of imposing a global carbon tax on international bunker emissions by employing a computable general equilibrium model approach. Under the assumption of an emissions reduction of 5 percent below 2000 levels by 2020, we demonstrate that a global bunker emissions charge, on one hand, reduces trade volume and change trade patterns between countries and regions, while on the other hand, accelerates the adoption of energy-saving technologies and reallocates the supply of international transportation services throughout the world. The net economic impact, though negative on average, is modest compared to the benefits obtained from the emissions reduction. If revenues from a bunker emissions charge are properly distributed among countries and regions, the losses to disadvantaged countries are likely to be offset by the benefits to advantaged countries. This finding provides useful insights for policy makers: a global bunker emissions charge could, in future, be an economically feasible strategy to reduce the increasing bunker emissions though the implementation requires more political effort and wisdom.

Key Words: Bunker Emissions Charge; International Maritime Transport; Economic and Trade Impact; CGE Model. JEL Code: N70, C68, F64 


\section{Highlights}

A global bunker emissions charge is a more plausible approach than unilateral bunker emissions charge

Economic impacts due to diverting of international trade and acceleration of energy-saving technologies

Reallocation of transportation services is another cause of the economic impacts.

Negative net economic impact is unevenly distributed, but modest compared to emissions reduction benefits

Revenue distribution arrangements is important for the success of a bunker charge's implementation. 


\title{
Re-analyzing the Economic Impact of a Global Bunker Emissions Charge
}

\author{
Yu SHENG ${ }^{\text {a }}$, Xunpeng SHI ${ }^{\text {b,c,d }} *$, Bin $\mathrm{SU}^{\mathrm{d}}$
}
a. School of Advanced Agricultural Sciences, Peking University.
b. University of Technology Sydney, Australian China Relations Institute, Ultimo 2007, Australia.
Email:xunpeng.shi@gmail.com
c. School of Low Carbon Economy, Hubei University of Economics, Wuhan, China.
d. Energy Studies Institute, National University of Singapore, Singapore 119620.

\section{[Abstract]}

Regulating bunker emissions continues to be a challenging task, largely due to the lack of a globally coordinated scheme providing economic and political incentives to potential participating countries. This paper analyses the economic costs and benefits of imposing a global carbon tax on international bunker emissions by employing a computable general equilibrium model approach. Under the assumption of an emissions reduction of 5 percent below 2000 levels by 2020 , we demonstrate that a global bunker emissions charge, on one hand, reduces trade volume and change trade patterns between countries and regions, while on the other hand, accelerates the adoption of energy-saving technologies and reallocates the supply of international transportation services throughout the world. The net economic impact, though negative on average, is modest compared to the benefits obtained from the emissions reduction. If revenues from a bunker emissions charge are properly distributed among countries and regions, the losses to disadvantaged countries are likely to be offset by the benefits to advantaged countries. This finding provides useful insights for policy makers: a global bunker emissions charge could, in future, be an economically feasible strategy to reduce the increasing bunker emissions though the implementation requires more political effort and wisdom.

Key Words: Bunker Emissions Charge; International Maritime Transport; Economic and Trade Impact; CGE Model.

JEL Code: N70, C68, F64

\section{Introduction}

To reduce the carbon emissions from the international transport industry sector, rigorous analysis of the economic impacts of a global bunker emissions charge under a global policy framework and coordination scheme is essential. Due to the rapid expansion of international trade in recent decades, international aviation and shipping services have significantly increased their 
consumption of bunker fuels — mainly fossil fuels — and have concomitantly greatly increased global greenhouse gas (GHG) emissions. In 2005, emissions resulting from the combustion of bunker fuels by the international aviation and shipping industries were estimated to have accounted for about 2.1 percent of global GHG emissions and 2.7 percent of global carbon dioxide (CO2) emissions (IEA, 2009). While the contribution of the international transport industry sector to global GHG emissions increased to only 2.4 percent between 2007 and 2012 (IMO, 2014), this proportion is expected increase to around 17 percent by 2050 if no action is taken to reduce the emissions (European Parliament, 2015).

Although the steady increase in the bunker emissions has gradually aroused public concern, there seems to be a global consensus that the notion of "environmental externality" prevents these emissions from being included in the national inventory of GHG emissions for any individual country (IMF, 2016; Lee et al., 2013; Shi, 2016). Bunker emissions are generated from mobile sources and are therefore emitted across national borders and throughout international airspace and waters. To correct for this environmental externality, an effective bunker emissions charge must be designed on the basis of a global framework and coordination scheme (Psaraftis, 2012). On one hand, a global bunker emissions charge, irrespective of whether a country supplying the service has priced carbon in its domestic market, will prevent transportation companies from rent seeking - creating hubs in exempt nations to avoid the surcharge (Australian Government, 2008). On the other hand, implementing a global bunker emissions charge will raise funds to support international cooperation in the development and transfer of cleaner technologies (i.e. solar energy) between developed and developing countries and reduce carbon emissions. 
While efforts have been devoted to establishing a mechanism for international cooperation in the control of bunker emissions, the emissions are still unpriced at a global level due to the lack of a globally enforceable scheme (Australian Government, 2008). For example, the Kyoto Protocol requires that developed countries must reduce, by working through international organizations, the emissions associated with the consumption of bunker fuels (UNFCCC, 1998). However, bunker emissions steadily increased by more than 50 percent from 1998 to 2007 (European Parliament, 2015). The challenge is how to gain universal support from all the potential participants, especially developing countries which are more likely to be disadvantaged, and those countries that are far from their trading partners.

To implement a global bunker emissions charge, it is essential to provide economic incentives to the potential participants. Thus, analyzing the impact of a global framework and its distribution across countries, from an economic perspective, is critical not only in policy debates, but is also important in the academic literature. Theoretically, extending the global carbon-emissions control framework to cover a bunker emissions charge, on one hand, will increase the cost of transporting goods and international travel. This may reduce and divert the demand for imported goods and thereby change global trade patterns - particularly for bulky commodities. On the other hand, imposing the bunker emissions charge may alter the supply of global international transportation services between countries, change the use of different types of bunker fuels, and affect the adoption of energy-saving transportation technologies, thereby affecting economic growth across regions. The net economic effects of implementing an emissions reduction policy and its cross-regional distribution are ambiguous and are subject to strictly empirical scrutiny. 
This paper employs a dynamic global computable general equilibrium (CGE) model, namely the Global Trade Environmental Model (GTEM), to quantify the economic impacts of imposing a global bunker emissions charge by 2030. In addition, we also discuss whether a global emissions charge could become a boon to all potential participants if the revenue from the bunker charge is properly distributed among countries and regions to offset the potential losses to the disadvantaged participants, in particular those from the developing world. The purpose here, therefore, is to assess the feasibility of a global bunker emissions charge from an economic perspective, though we recognize that the implementation of a framework would require considerable political effort and wisdom. ${ }^{1}$

We show that a global bunker emissions charge may incur only limited economic and trade costs and be economically feasible and desirable relative to the benefits from emissions reduction and revenue collection. It also shows that a global bunker emissions charge with proper redistribution arrangements could even out the economic impact across countries, thus providing the supportive evidence for a non-differential treatment principle in reducing bunker emission.

Our paper makes at least two contributions to the literature. First, it is a pioneer study which quantifies the economic effects of implementing a global bunker emissions charge and its crosscountry distribution from a general equilibrium perspective. The existing literature focuses mainly on using regression analysis to investigate, from various angles, the social benefits of a

\footnotetext{
${ }^{1}$ It is important that a bunker emissions charge be universally applied irrespective of whether the country supplying the service has priced carbon in its domestic market in order to prevent transportation companies from rent seeking by creating hubs in exempt nations so as to avoid the charge (Climate Works 2009).
} 
mitigation policy, while ignoring its general equilibrium effects. Nor do the previous studies account for the inequalities that a global bunker emissions charge would generate between countries and regions, which could discourage the participation of disadvantaged economies.

Our study investigates the economic impact of a bunker emissions charge by using a dynamic CGE model to assess its general equilibrium effects and the cross-regional distribution to inform policy making. It also provides useful insights for the policy debate on how to make a global policy scheme feasible in practice. Specifically, it points to the use of a revenue redistribution tool to reduce cross-regional disparity, compensate for the losses and encourage participation. In practice, there are increasing concerns about the use of the non-differential treatment principle as the policy base to manage the international transportation industry. However, since a global bunker emissions charge is likely to generate asymmetric costs for different countries and regions (mainly, developing countries), it will discourage their participation.

The rest of the paper is organized as follows. Section 2 reviews the debate over the relevant economic, environmental and political issues. Section 3 describes the attributes of the dynamic CGE model in this study, which enable us to analyze the net economic impact of a global bunker emissions charge and its cross-country disparity. The policy scenarios, modelling sensitivities and data sources are also provided. Sections 4 and 5 present the model simulation results and discuss the impact of imposing a bunker emissions charge on international trade, competitiveness/comparativeness and the social welfare of individual participants. Concluding comments and recommendations are provided in Section 6. 


\section{Regulating Bunker Emissions: Policies and Literature}

Aviation and maritime shipping activities are critical elements of global trade and business, and nowadays more than 90 percent of commodity trade is transported by sea or by air (ICS, 2014; Monkelbaan, 2010). Due to global economic growth, this rapidly expanding sector has significantly increased its consumption of fossil fuels in recent decades, making it an important source of GHG emissions. Under the United Nations Framework Convention on Climate Change (UNFCCC) process, the share of emissions from bunker fuels has been raised since the first meeting of the Conference of the Parties (COP) in 1995. Article 2.2 of the Kyoto Protocol mandates that developed countries (or Annex I countries) limit or reduce their GHG emissions (not controlled by the Montreal Protocol) resulting from the consumption of aviation and marine bunker fuels. To facilitate implementation of this protocol, the International Civil Aviation Organization (ICAO) and the International Maritime Organization (IMO) were authorized to undertake various policies and measures to reduce GHG emissions resulting from the combustion of aviation and marine bunker fuels, respectively (UNFCCC, 1998).

To date, the IMO and ICAO have generally considered two typical policies to reduce bunker emissions: market-based measures (MBMs) and technical and operational measures (mainly efficiency requirements) (Psaraftis, 2012). Over the past two decades, the IMO has been successful in implementing technical and operational measures. The Energy Efficiency Design Index (EEDI) for new ships and the Ship Energy Efficiency Plan (SEEMP) for all ships were introduced in 2011 and became effective on 1 January 2013 (IMO, 2017). By contrast, the IMO has not implemented a MBM to control bunker emissions from the shipping industry. The discussions on MBMs and related issues were suspended after the $65^{\text {th }}$ session of the IMO 
Marine Environment Protection Committee due to controversies surrounding the distribution of costs and benefits among countries (Shi, 2016).

Restriction of GHG emissions from the international transportation sector is essential to reduce global carbon emissions, but difficult. It is widely believed that 'applying operational measures and implementing advanced engine technologies could lead up to 75 percent savings in energy consumption and $\mathrm{CO}_{2}$ emissions' (IMO, 2009b). However, it remains a challenging task to enforce the adoption of energy-saving technologies and regulate the emissions of the international transportation sector in practice. This is because fossil fuels (or bunker fuels) consumed by the international transport sector do not belong to any country and cannot be accounted for in emission reductions unilaterally (IMF, 2016). The regulation of bunker emissions is also more challenging than the technical and operational measures due to a lack of economic incentives for shipping operators (as the bunker fuel change may increase operation costs) and thus requires intensive international cooperation under a global climate policy framework.

Given the difficulties in reaching an agreement on international marine emissions regulations, various alternatives have been proposed, such as the Vessel Efficiency System, Port State Levy (IMO, 2017; Psaraftis, 2012), and a unilateral limit for all ships entering European Union (EU) ports (Cariou and Cheaitou, 2012). The EU is calling for a global approach to reducing the GHG emissions caused by international shipping and plans to require that large ships using EU ports must report their verified annual emissions and other relevant information from 2018 (European Parliament and Council of the European Union, 2015). There are also discussions underway on 
country-specific policies that could lead to reduced shipping emissions (Gilbert and Bows, 2012). As an interim measure, the IMO has gained members' support to develop a global data collection system to measure $\mathrm{CO}_{2}$ emissions from individual ships (ICS, 2014). However, none of the aforementioned can replace a global climate policy framework.

A global carbon tax regime that facilitates the implementation of MBMs has long been under discussion. The shipping industry prefers a mechanism linked to fuel consumption, rather than a system based on emissions trading, since the latter will cause additional complications in the calculation of emissions (ICS, 2014). In January 2016, the International Monetary Fund (IMF) called for a global carbon tax scheme on shipping and aviation with the aim of raising public resources for climate finance. Differing from other proposals, the proposed tax framework paid additional attention to the bunker charge revenues and their use for compensating developing countries. The IMF argued that approximately US\$25 billion could have been raised in 2014 with a global tax of US\$30 per ton of $\mathrm{CO}_{2}$ applied to these fuels (IMF, 2016).

Developing countries and island countries have raised two concerns regarding the implementation of a bunker emissions charge. First, developing countries are worried about the potential unfair burden placed on their economic development. For example, Brazil and India argued that a proposed MBM under the IMO would not be compatible with the UNFCCC principle of common but differentiated responsibilities (CBDR) and would impede food security in developing countries (IMO, 2014). Second, the disbursement of revenue remains a controversial issue although there was a general preference that the greater part of any funds 
generated by an MBM under the support of the IMO should be used for climate change adaption and mitigation purposes in developing countries (IMO, 2009a). This is because there is conflict between the IMO approach of universal application and the CBDR principle of UNFCCC. In sum, the IMO members cannot reach a consensus on an MBM until the potential economic impact of implementation and its cross-country distribution are understood. This reflects the compelling need of further studies.

However, there are yet only a few studies examining the impact of various global policy measures for reducing international bunker emissions. For example, Psaraftis and Kontovas (2010) studied the implications of various emissions reductions policies for maritime transportation and identified the trade-off between environmental performance and economic costs. Miola et al. (2011) conducted an in-depth analysis of various proposed policy instruments designed to reduce the emissions, focusing on economic theory, legal principles and technological options. They concluded that permits should be auctioned frequently, emissions trading should spare small emitters, and inclusion of shipping in the EU Emission Trading System (ETS) causes carbon leakage. Franc and Sutto (2014) explored the potential impacts of a cap-and-trade system on the organisation of containerised shipping lines and European ports. Wang (2010) estimated the economic costs of reduceing shipping emissions for non-Annex countries with a focus on the common but diffierential principal and found that small island countries were more likely to be affected by increasing shipping costs.

Unlike any of the previous studies, this paper attempts to fill this gap by assessing the global impact of a bunker emissions charge with a customized dynamic CGE model. In particular, we 
propose to answer questions such as: how much could a global bunker emissions charge negatively affect world trade and economic development? To what extent could a MBM disadvantage consumers and industries in developing countries that often export low value bulky commodities (IMO, 2014)? Moreover, if an MBM is to generate adverse impacts, would it be more serious for countries situated in remote locations and with high levels of trade dependence, such as some Small Island Developing States (SIDS) (Monkelbaan, 2010)?

Our study is also related to another strand of literature which used CGE models to support energy and environment policy analysis in areas such as taxation, subsidies, market reform, technology spillover, regional cooperation, and others (Araar et al., 2011; C and Kelly DL, 2012; Carbone and Kerry, 2013; Sue Wing, 2009). These studies mainly focused on the national GHG inventory in evaluationg the impacts of carbon pricing mechnisms. See, for example, Goulder (1995) on the United States' carbon tax, Böhringer and Rutherford (1997) on Germany's carbon tax, Allen Consulting Group (2006) on Australia's carbon tax, Allan et al. (2014) on Scotland's carbon tax, Alton et al. ( 2014) on South Africa's carbon tax and Liu Y and Lu Y (2015) on China's carbon tax. Some recent studies apply the static multi-region CGE model to study transport related emissions. For example, Abrell J (2000) analyses the impacts of market-based regulation instruments on transportation $\mathrm{CO}_{2}$ reductions; Lee et al. (2013) evaluate the economywide impact of a carbon tax on international container shipping for world countries; and Lee et al. (2016) investigate Asian economic integration and its impacts on martime $\mathrm{CO}_{2}$ emissions. However, to the best of our knowledge, no previous studies have used a dynamic multi-region CGE model for worldwide countries and have therefore not been able to estimate the economy wide impact of a bunker emissions charge or levy. 


\section{Model Framework: GTEM}

In this paper, we employ the Global Trade and Environment Model (GTEM) to quantify the economic impacts of imposing a global bunker emissions charge on major countries and regions. What follows is a brief description of the model features related to analyzing a global bunker emissions charge, followed by a discussion on how to develop alternative scenarios to quantify the economic impacts of imposing a global bunker emissions charge and a review of the main data sources.

\subsection{Model Settings}

GTEM is a multi-country, multi-sectoral, recursively dynamic CGE model of the world economy that is widely used to analyze policy issues with global implications, such as global trade policy changes and issues that involve long time horizons such as climate change mitigation. The core model consists of well-designed modules defining the production, consumption and trade of each commodity in each country and also the international transportation sector, as documented in Pant (2007).

The model can be used to analyze the global bunker emissions charge because it details the GHG emissions mechanism from the international transportation service sectors that accounts for major fuels and sources, allows for technology substitution and uptake of backstop technologies, 
and incorporates various climate change response policies. For simplicity, we offer a brief discussion of the model setting with a focus on international transportation sector.

In the current model setting, there are 13 regions plus an area of 'international waters', and all commodities and services are categorized into 21 commodity groups (Table 1). 'International waters' are a hypothetical region where global traders operate and use international shipping services to ship goods from one region to the other. The global transport sector operates in 'international waters', and is separated from the domestic transportation sector. It receives its income from global traders who transport the merchandise from source regions to their respective destinations.

Table 1: GTEM regional and commodity disaggregation

\begin{tabular}{ll}
\hline Regions & Commodities \\
\hline United States & Coal \\
European Union 25 (EU25) & Oil \\
China & Gas \\
Former Soviet Union (FSU) & Petroleum and Coal Products \\
Japan & Electricity \\
India & Iron and Steel \\
Canada & Non-ferrous Metals \\
Australia & Chemicals, Rubbers and Plastics \\
Indonesia & Other Mining \\
South Africa & Non-metallic Minerals \\
Other Southeast Asian Countries (Other & \\
SEA) & Manufacturing \\
OPEC & Other Transport \\
Rest of world (ROW) & Domestic Water Transport \\
& Domestic Air Transport \\
& Crops \\
& Livestock \\
& Forestry and Fisheries \\
& Food \\
& Services \\
& International Water Transport
\end{tabular}


Source: GTAP Model.

To provide the service, the global transport sector purchases transport commodities from various regions and pays the regions for the supplies of actual inputs (including capital, labor and fossil fuel). The demand for inputs from regions by the international shipping industry is derived by minimizing the cost subject to a constant elasticity of substitution (CES) production function. A constant elasticity of substitution between regional supplies of each primary factor input (such as labor and capital) and energy-factor inputs to the global transport sector is used to determine the response of the supply from different countries.

The cost (or revenue) of international transport is added to the cost of imports to each country. The demand for international transport is proportional to the quantity of goods transported from one region to the other. In other words, the percentage change in demand for transport service for goods transported between any two regions is set equal to the percentage change in the quantity of the commodity transported. This relation is also determined by technological changes in the international transportation sectors, captured by various productivity parameters for transportation technological progress. The total demand for international transport services is the sum of the demand for transport services induced by exports of all commodities along all possible routes.

The zero-profit condition for these global transportation sectors implies that the cost of supplying the margin transportation services should be equal to the revenue received from employing the service in transporting the merchandise. 
In this sense, the model in use here differs from the GTAP model and other general equilibrium models by providing a transparent mechanism to link energy consumption to the production of international transportation services. Thus, it can be used to analyze issues such as the impacts of a global bunker emissions charge on international trade and social and economic welfare, as well as the uptake of new technologies, throughout the world.

Finally, the fossil fuels consumed by the international water and air transport sectors, are defined as bunker fuels and are identified by using the commodity level information on coal and petroleum oil (including heavy oils). It is worth noting that the outputs of international water and air transport sectors are both used for transporting goods from one region to the other. ${ }^{2}$ In this sense, these two sectors are both international margin sectors and there could be a switch in demand between the two sectors according to their relative price.

Based on the model setting of the international transport sectors, an emissions charge on bunker fuel will generate a general equilibrium impact on the global economy from three perspectives: (a) the bunker charge will decrease demand for international transportation and thus reduce trade because it increases transportation costs. (b) the bunker charge will change the relative supply of the international transportation services from each region through affecting the price of bunker fuels and thus the cost minimization process for each region to supply the international transportation services. (c) the bunker charge will alter the structure of demand and supply for

\footnotetext{
${ }^{2}$ In CGE models, the international transportation sectors are always assumed to be margin sectors which are used to absorb the gap between imports and exports in statistics.
} 
international transportation services, since different countries/regions have different transportation technologies and different prices for bunker fuels.

\subsection{Scenarios for Simulations}

The model simulation is run under certain scenarios to investigate the economic impacts of imposing a global bunker emissions charge. The baseline scenario assumes that the bunker emissions charge is implemented via a uniform global carbon charge rather than emissions trading. This assumption helps to avoid issues arising from inappropriate initial quota allocation before international emissions trading is allowed between countries.

Specifically, the basic scenario assumes that all countries implement an ad-value bunker emissions charge from 2010 (18 US\$/ton- $\left.\mathrm{CO}_{2}\right)$ in a staged manner across regions as described in the Australia Low Pollution Future Report (Garnaut, 2008). The basic scenario follows the Carbon Pollution Reduction Scheme-5 (CPRS-5) scenario, which assumes a slower start to global emissions reductions and stabilization at $550 \mathrm{ppm}$ and Australia's medium-term target at 5 percent below 2000 levels by 2020 . Under this scenario, the global carbon charge on bunker emissions is assumed to grow at around 4 percent a year. Moreover, the bunker emissions charge revenues collected in all countries are assumed to be pooled and distributed back to developing countries in proportion to their share of imports in global trade, while the shares that may accrue to the developed countries are then distributed back to the developing countries in proportion to their share in the total population and their efforts in reducing bunker emissions. For comparison, two alternative scenarios are also developed based on different assumptions with respect to 
emissions accounting methods by flag (i.e. the developed countries flag to impose the bunker charge first, followed by the developing countries) and by harbor of destinations/origins.

To split the impact of the global bunker emissions charge from other macroeconomic shocks, we simulate the model twice under each scenario - once without the bunker emissions charge (or the reference case) and the other with the bunker emissions charge (or the comparison case). The comparison between the outcomes obtained from these two runs for each scenario provides a measure of the relative economic impacts of including bunker emissions in the purview of a bunker emissions charge on global carbon emissions reduction, a bunker emissions charge on revenue collection, global trade amount and patterns, and the competitiveness of different commodities in major countries and regions.

Besides the basic scenarios, two more sets of scenarios are designed to examine whether the net impacts of imposing a global bunker emissions charge will change with the assumed carbon charge path, variations in bunker fuel prices and the method used to re-distribute the bunker charges revenue between countries.

Impact on carbon charge path: To test this issue, we run the model under the same global environment as in the basic scenario, but with two different starting carbon emissions charges. The first is about 40 percent higher than the starting carbon charge under the basic scenario (i.e. $25 \mathrm{US} \$ /$ ton- $-\mathrm{CO}_{2}$ ), the second is about 45 percent lower (i.e. $10 \mathrm{US} \$ /$ ton- $-\mathrm{CO}_{2}$ ). The higher carbon charge reflects the carbon charge under the CPRS-15 scenario (Australian Government, 2008), while the lower carbon charge reflects the case when there is little progress in international 
cooperation on developing a universal global framework under the CPRS-5 scenario. In both cases, the model is simulated twice, with and without applying the global carbon charge to bunker emissions. These two sets are referred to as high and low carbon charge scenarios.

Impact of revenue redistribution: How the revenues collected from the bunker emissions charge is redistributed among countries and regions matters for the simulation results. In current policy debates, some argue that the countries which collect the revenues should have more allocations so as to give the incentive to implementation, while others argue that the service providers should get more allocation since they have undertaken the largest proportion of the costs associated with providing the services. Alternatively, it is argued that the revenue should be evenly distributed between countries for the purpose of fairness. A comparison of the simulation results obtained from these alternative options with the baseline model can provide the guidance on which option would be more beneficial to the world as whole and also give more incentives to potential participants.

Impact of changing global oil prices: It is widely acknowledged that the international shipping industry is moving from using heavy fuel oils (HFO) to marine gas oil (MGO) under the MARPOL Annex VI regulations. Since there are uncertainties about future global oil prices in general and MGO prices, the model simulation without accounting for possible change in global bunker fuel price will generate significant bias. To deal with this problem, we incorporate two additional possible price scenarios, derived from the estimates developed by the IMO Expert Group on Market Based Measures (IMO, 2014). The first price scenario assumes a low-price projection; the second price scenario assumes a high price path. Still, the baseline scenario was 
run with a reference marine fuel price as well to evaluate the sensitivity of our model outcomes to various possible marine fuel prices. ${ }^{3}$

Piecing everything together, we use 12 scenarios in total running in 3 sets to include 3 baseline scenarios, 3 scenarios for accessing the revenue distribution arrangements and 6 scenarios for the trajectory test (Table 2). All scenarios were simulated over the period spanning 2010 to 2030. The global bunker emissions charge in the baseline scenario was implemented in line with the assumptions underlying the Garnaut Climate Change Review (Garnaut, 2008) scenario that the global GHG emissions by 2020 will decrease to 5 percent lower than the 2000 level. All developed countries were assumed to introduce a carbon charge in 2010, while developing countries were assumed to introduce a carbon charge progressively from 2015 onwards. By 2025 all countries are participating fully. However, it is further assumed that bunker fuels purchased in all regions, whether the region has taken up the global carbon charge or not, are subjected to the bunker emissions charge from the year 2010.

Table 2: Summary of scenarios for model simulation

\begin{tabular}{lll}
\hline Set & $\begin{array}{l}\text { Scenarios } \\
\text { Baseline scenario } \\
\text { (CPRS-5 as } \\
\text { Benchmark) }\end{array}$ & $\left.\begin{array}{l}\text { Description } \\
\text { an ad-value global bunker emissions charge } \\
\text { from } 2010(18 \mathrm{US} \$ \text { ton-CO }\end{array}\right)$ \\
\hline Revenue collection & $\begin{array}{l}\text { By flag } \\
\text { By harbor of } \\
\text { destination/origin } \\
\text { Full refund }\end{array}$ & $\begin{array}{l}\text { Bunker emissions charge is collected by flag } \\
\text { Bunker emissions charge is collected by } \\
\text { harbors of destination or origin } \\
\text { Redistributing revenue according to the } \\
\text { revenue collection }\end{array}$ \\
\hline
\end{tabular}

\footnotetext{
${ }^{3}$ The results are reported in Appendix A.
} 


\begin{tabular}{|c|c|c|}
\hline & $\begin{array}{l}\text { Developing countries } \\
\text { sharing } \\
\text { Evenly distributed }\end{array}$ & $\begin{array}{l}\text { Redistributing revenue only to the developing } \\
\text { countries according to their trade share } \\
\text { Redistributing revenue to all countries and } \\
\text { regions evenly }\end{array}$ \\
\hline $\begin{array}{l}\text { Carbon charge } \\
\text { path/global oil price } \\
\text { change } \\
\text { (sensitivity test) } \\
\text { (Presented in } \\
\text { Appendix) }\end{array}$ & $\begin{array}{l}\text { High/low carbon } \\
\text { charge scenarios } \\
\text { High/low price path } \\
\text { High/low trajectory } \\
\text { test }\end{array}$ & $\begin{array}{l}40 \text { percent higher vs. } 45 \text { percent lower; } \\
\text { Extreme high/low oil price } \\
\text { High (low) trajectory }\end{array}$ \\
\hline
\end{tabular}

Note: In each scenario, both the reference and comparison cases are run and the difference is considered the impact.

\subsection{Data Sources}

The data used in this paper are mainly from three sources. The first group of data is used to calibrate the GTEM model: the data for trade and production are primarily from the GTAP database; the data on energy consumption and emissions are estimated using the country-specific national account statistics on the production and consumption of energy products to feed the GTEM model.

The second group of data is used to construct the scenarios for a "bunker charge". The estimates were made based on the Carbon Pollution Reduction Scheme scenario that stipulates an emissions reduction of 5 percent below 2000 levels. The data used for this purpose is mainly from the Australian Treasure Estimates: "Australia's low pollution future: the economics of climate change mitigation". Please refer to the CSIRO (2008) and Commonwealth of Australia (2008) for a detailed methodology and the data sources used in these estimates. The third group of data is related to other descriptive statistics which come from different data sources including the IEA (2009), UNFCCC (2015), etc. 
Three specific features of the data collection are required to be mentioned as below. First, the GTEM emissions database was expanded to identify and include emissions associated with bunker fuels. In accordance with the Kyoto Protocol, the standard version of the GTEM database excludes bunker fuel related emissions. In this paper, we start with the simulation from 2009 (the same base year as for the standard GTEM database) and shift it to 2015 to reflect the real practice. Then, we allocate these emissions to the international water and air transport sectors in proportion to their fuel usage.

Second, the scheduled change in bunker fuel standards, from HFO to MGO, is essential to our simulation and is therefore included in this modelling exercise in an indirect way. We used this approach because the fuel types are not separately identified in the GTEM commodity groups. All bunker fuels are grouped into petroleum and coal products. The progressive change to MGO, which is designed to reduce mainly sulfur emissions from bunker fuel combustion, will increase the unit cost of marine fuel by 215 percent between 2010 and 2030. These standards are assumed to be fully implemented by 2020 , however the price of MGO is projected to rise over the entire projection period to 2030. Since a bunker emissions charge has no impact on GHG emissions or fuel efficiency, these features have been incorporated in this modelling exercise by increasing the user levies on bunker fuels and the purchase of petroleum and coal products by the international water transport sector, so that the user price in the business as usual case rises to reflect the change in standard. 
Third, the economic effects of the bunker emissions charge will be determined by assumptions pertaining to the distribution of the revenues arising from the bunker emissions charge. Even under the basic scenario that the revenues should be distributed in a way which is favorable to developing countries, it could be treated in different ways. In our exercise, we choose to redistribute the revenue in proportion to the share of their imports relative to all imports of Annex I countries. This assumption reflects, in a simplistic way, a policy where revenues from a bunker emissions charge are used to partly compensate for the possible adverse impacts of a bunker emissions charge on developing countries and partly to support adaptation and mitigation efforts in developing countries.

\section{Mechanism and Impact of a Global Bunker Emissions Charge}

Using the basic scenario, we simulate the model with both the reference and the comparison assumptions. The difference in the two baseline simulations (i.e. with or without a global bunker emissions charge) therefore yields its likely impact on emissions reduction, revenue collection and economic/trade outcome. For the other two scenarios associated with imposing the charge by flag or by destinations/origins, the comparison is made only with the reference case (e.g. without a global bunker emissions charge). All results in the following section should be interpreted as the relative impact of charging bunker emissions to the basic scenario. 


\subsection{Emission Reduction and Revenue Collection}

To examine its economic effects, we first run the simulation with and without imposing the price shock resulting from the bunker charge. Global bunker emissions are projected to decline with the implementation of a bunker emissions charge for three reasons. The main reason is that the implementation of this charge will first push up air and sea freight costs and in turn reduce the demand for bunker fuels and the related GHG emissions, or the 'output reduction' effects.

Thereafter, the relative supply of international transportation services between these margin sectors and across countries and the associated bunker fuel consumption will shift towards the sectors and countries/regions with the relatively lower input costs under the bunker emissions charge and with a relatively quick adoption of energy-saving technologies, or the 'supply adjustment' effects. In the long-term equilibrium, a dynamic adjustment in investment will also help to improve the energy consumption efficiency of international transportation sectors throughout the world, or the 'technological progress' effects, though the impact through this channel is indirect and relatively small compared to the former two effects.

Figure 1: Global bunker emissions under the basic scenario

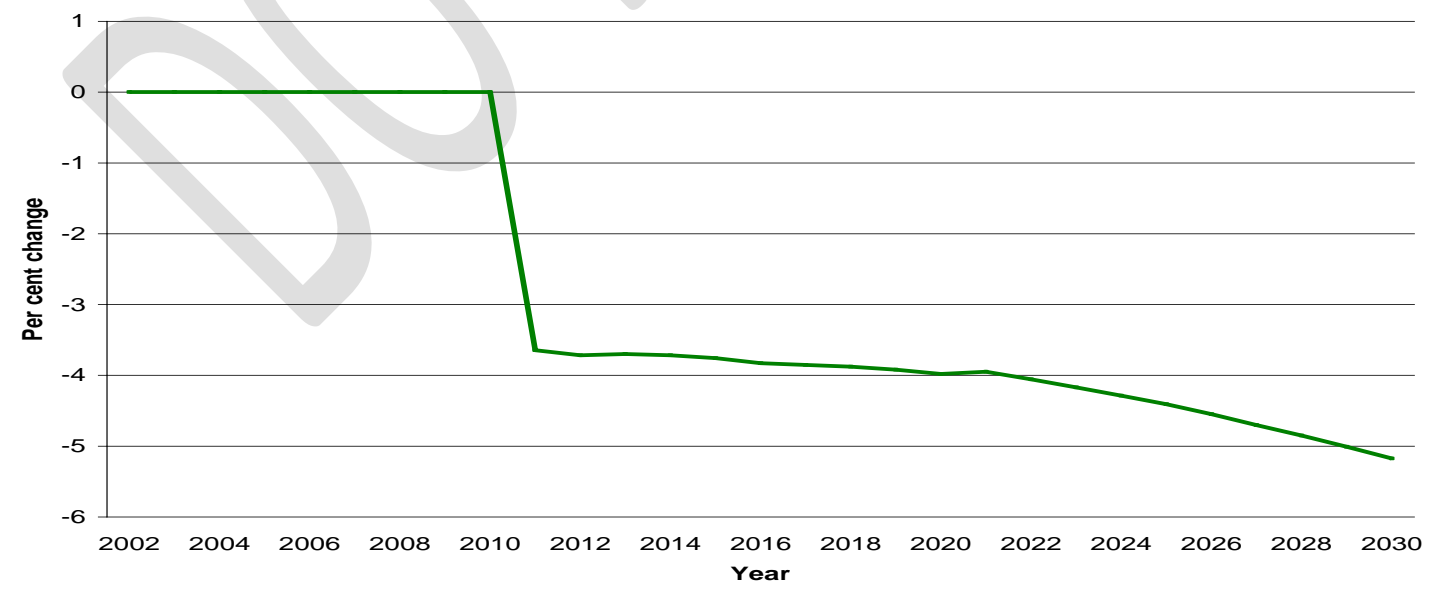


Note: the model result is presented as the relative change from the baseline scenario without a bunker emissions charge.

Figure 1 illustrates the projected decrease of global bunker emissions relative to the baseline scenario. In the first year of implementation (or 2010), bunker emissions fall by 3.6 percent, mainly by output reduction effects. In subsequent years, the rate of decline is moderated because the carbon charge rises only by 4 percent per year, and thus the subsequent changes in the price of imported commodities are not as high as in the first year. However, the accumulated effects in carbon emissions reduction continues to increase due to the supply adjustment effects and technological progress effects. By 2030, bunker emissions fall by an estimated 5.2 percent relative to the emissions for that year in the CPRS-5 scenario without the bunker emissions charge. It is worth emphasizing that these reductions are relative to the reference case.

Along with the reduction in bunker emissions, another benefit obtained from imposing a global bunker emissions charge is the revenue generated. Figure 2 provides estimates of the revenues from the bunker emissions charge collected by all regions in 2030. That year, an estimated US\$75 billion (in 2001 dollars) throughout the world could be collected from the tax on bunker emissions, compared to the estimate of US\$19 billion in 2010 . The three-fold increase in the revenues from the bunker emissions charge over the 20 years is partly explained by the 4 percent annual growth in the charge rate and the growth of bunker fuel consumption arising from increased international transport services for goods. 
Figure 2: Collection of bunker revenue by region in 2030 under the basic scenario (Unit: US \$billion at 2001 prices)

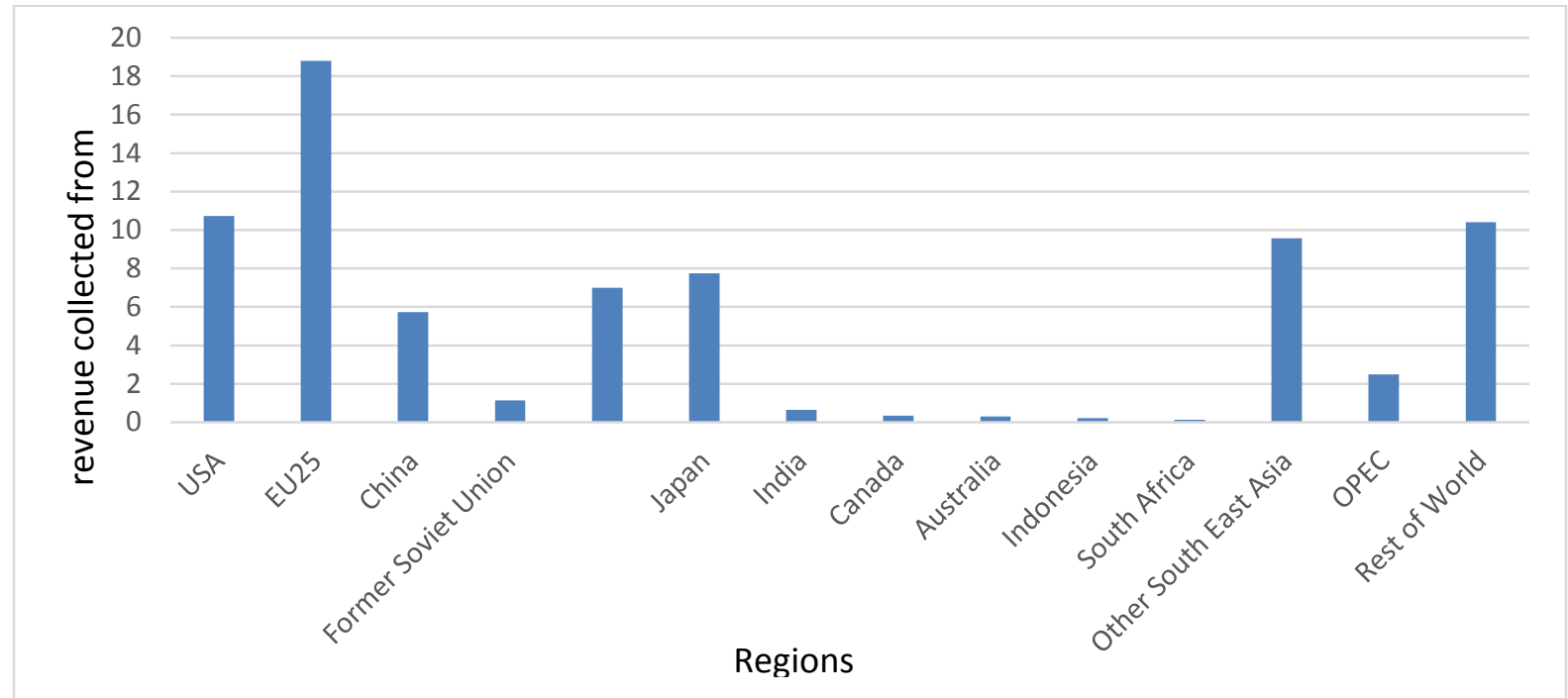

At the regional level, the East Asian countries (including Japan, China and other Southeast Asian countries) contribute the largest proportion of revenues collected from the bunker emissions charge (30.6 percent), followed by the EU 25 countries (25.0 percent) and the United States (14.3 percent). The rest of the world summed together accounts for only 30.1 percent of the total revenues. This outcome is a consequence of the fact that the three regions, including the EU25 countries, the United States and the East Asian countries will account for largest share of global trade by 2030 and dominate the supply of international transportation services when a global bunker emissions charge is in place. In this sense, technological progress in improving the energy use efficiency of international transportation and bunker fuel quality in the three regions is more essential to further reducing the bunker emissions. 


\subsection{Trade Volume Reduction and Diversion}

A bunker emissions charge is expected to incur economic costs for participating countries through the reduction in export and import volumes and diversion of trade between countries. These effects are generated through the effect of the bunker emissions charge raising freight costs and inducing a backward and forward shifting of the charge to alter the prices of importing and exporting commodities via the domestic production process. The shifting of the bunker emissions charge to exporters and importers and across all other market participants follows a general equilibrium process depending on the complex interaction of elasticities of supply and demand for all commodities and primary inputs. However, in the first order, the price elasticity of demand for imports and the price elasticity in the supply chain (and particularly which producers of exporting commodities are included) will explain a large part of the adjustment process.

Generally, the implementation of a bunker emissions charge is like an additional tariff that is differentiated by commodity and source. At first, it raises the cost of importing commodities from overseas and therefore encourages domestic production as substitutes. As the import substitution sector expands its production, prices of primary inputs (e.g. land, labor and natural resources) tend to increase due to intensified competition in factor markets. This in turn raises the costs to produce other commodities and thus pushes up the price of exporting commodities. Although the mechanism is transparent, the magnitude of the net impact depends on the overall change in import prices, primary input prices and the responsiveness of other commodities to input prices (in response to the bunker emissions charge). In addition, when facing the relatively higher transportation costs due to the bunker emissions charge, exporters, importers and domestic producers will also minimize the transportation and production costs by adopting the 
relatively more energy-efficient transportation methods and energy-saving technologies, which in turn help to offset the losses associated with the bunker emissions charge in the long run.

Figure 2 illustrates the net impacts of the bunker emissions charge on average import and export prices across countries under the baseline scenario. As expected in our model, import prices faced by all countries increase as a result of imposing the bunker emissions charge. This is due to the need for consumers to pay a certain proportion of the increased costs associated with transporting goods from overseas, even though the supply response may compensate for some costs. Moreover, increased import prices transfer into additional demand for domestic substitutes, which in turn increases the price of primary inputs and thus the production costs of exporting commodities.

As in Figure 3, export prices in most countries increased after imposing a bunker emissions charge, but the highest increase (in Japan) was still below 0.5 percent. As for the three exception countries including Australia, China, and Indonesia, they all shared a common feature, namely they faced relatively fewer constraints in the supply of primary inputs and lower export demand elasticities.

Figure 3: Responses of export and import prices to a bunker emissions charge under the basic scenario in 2030 


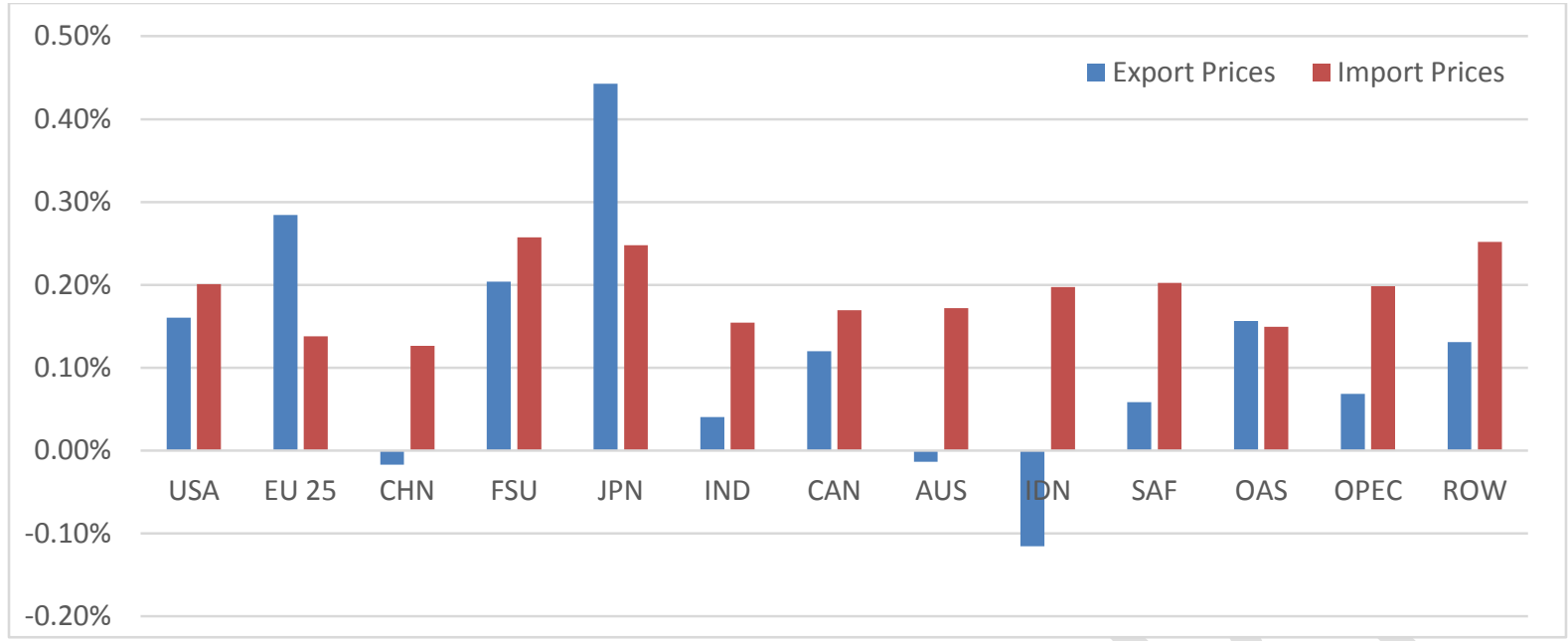

Note: the change is expressed as the logarithm of change from the baseline scenario without a bunker emissions charge.

The average rise in import prices faced by each region were simulated to be 0.2 percent higher by 2030 than they would be without the bunker emissions charge. In addition, changes to export prices in 10 of the 13 regions were smaller than those of import prices. This implies that the impact of imposing a bunker emissions charge on import and exports prices is not significant.

As the bunker emissions charge raises import and export prices, it will reduce average trade volume between countries. As shown in Figure 4, import and export volumes for all countries are projected to decline when the bunker emissions charge is imposed. As with the impact of the bunker emissions charge on import and export prices, the impact on import volumes was generally larger than that on export volume (though both of the declines were less than 0.4 percent).

Figure 4: Responses of export and import volume to a bunker emissions charge under the basic scenario in 2030 


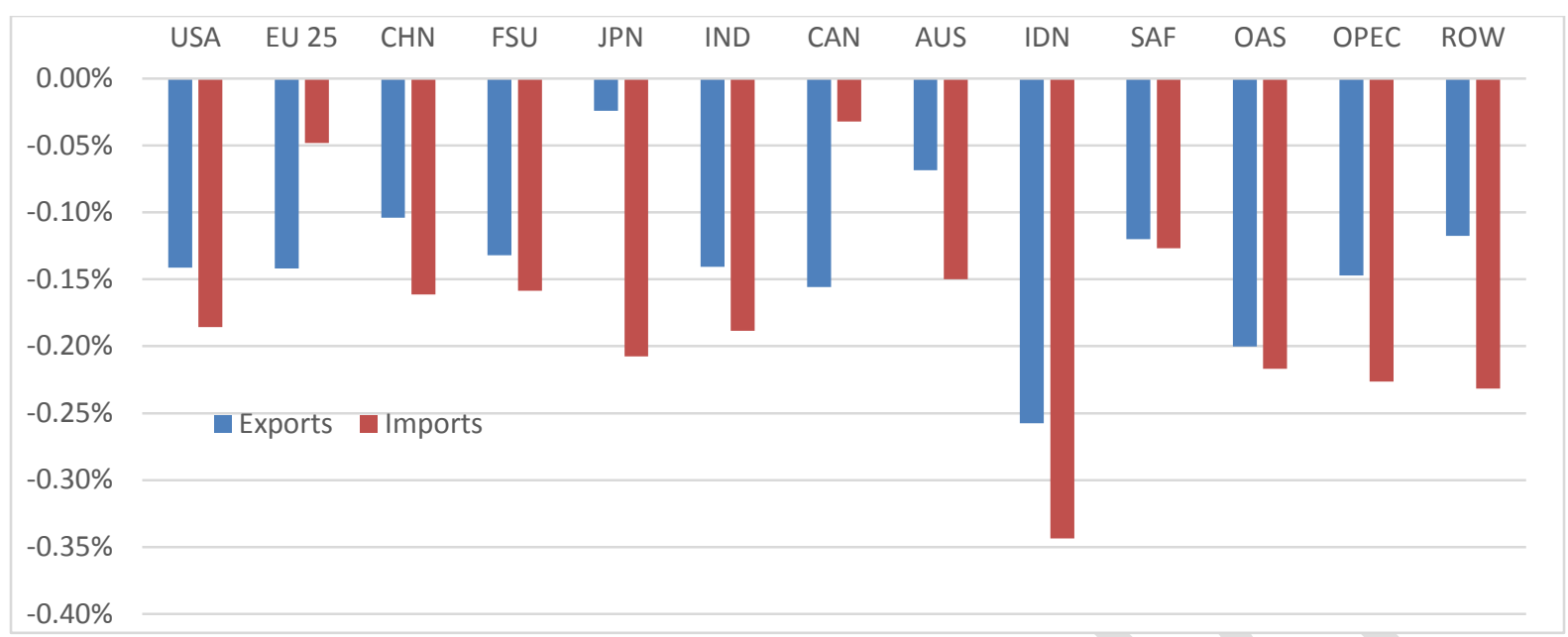

Note: the change is expressed as the logarithm of change from baseline scenario without a bunker emissions charge.

In addition to affecting the price and volume of trade, the bunker emissions charge could also divert trade between commodities and across regions. The key reason is that the emissions charge is based on bunker fuel consumption, and the transport of different commodities between different regions has different intensities in bunker fuel consumption. In addition, the substitutability in alternative ways of transportation, the response of technological progress in improving energy use efficiency, and the choice of imports and exports of substitutes from other regions also vary between commodities and across regions. As such, the bunker emissions charge will change the trade patterns of different commodities between regions in a complex way. Generally, the bunker emissions charge is more likely to reduce the trade of low-value highvolume commodities from relatively distant sources, while encouraging trade of high-value lowvolume commodities. The carbon charge on bunker emissions also encourages trade and production of those commodities which do not rely on international transport services, such as non-ferrous metals or services. 
As shown in Figure 5, the imposition of a carbon charge on bunker emissions is projected to slightly reduce global export volumes of coal, other mining products, crops and food, encouraging further processing before exporting. The magnitude of the decline in export volumes of these commodities is projected to be less than 0.6 percent relative to the baseline case in 2030. As these sectors begin to slow due to a decline in export demand, the release of some inputs used in their production will put downward pressure on commodity and primary input prices, lowering the unit cost of production for commodities that use international transport services less intensively. Consequently, exports of these high value-low volume commodities are expected to increase with a bunker emissions charges, relative to the reference case. Small increases in export volumes of iron and steel (about 0.2 percent), non-ferrous metals (about 0.1 percent) and services (about 0.1 percent) are projected. Changes to exports in other sectors, including natural gas, manufacturing and food are negligible. Finally, the relative geographic isolation between trading partners will also affect the role of the bunker emissions charge in redistributing trade between countries. The projected negative impacts together account for the supply-side response.

In sum, imposing a bunker emissions charge incurs costs for participating countries by reducing trade flows and diverting trade among commodities and across regions. However, as the results clearly indicate, the price effects are quite small due to either the supply response effects or the technological progress effects. Thus, its impact on trade is modest.

Figure 5: Effects on trade patterns from a bunker emissions charge under the baseline scenario in $2030(\%)$ 


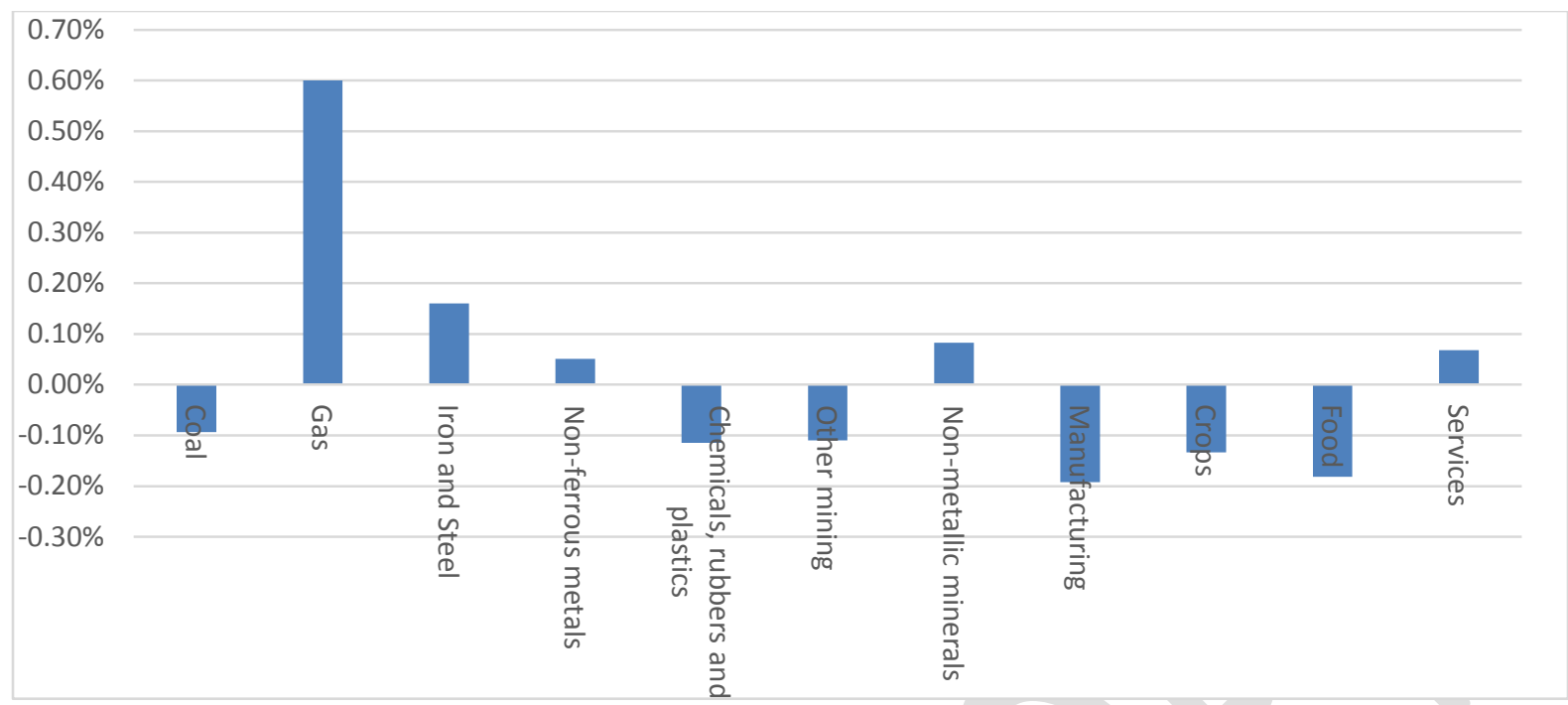

Note: the change is expressed as the logarithm of change from CPRS-5 without a bunker emissions charge.

\subsection{A Universal Charge versus a Partial Tax by Flag or by Destination/Origin}

What about the costs and benefits from imposing a bunker emissions charge if this global framework is implemented in an alternative way? To answer this question, we simulate the model by assuming that the bunker emissions charge is collected by flag (for example voluntarily by countries/regions which are willing to impose the charge) and by harbors of destination or origin, instead of the universal charge. The simulated results obtained from these alternative scenarios are then compared to those obtained from the baseline scenarios.

Figure 6 compares the reduction in global bunker emissions among the scenarios of collection by flag, by destination/origin and the benchmark scenario. Although all three simulations start with the same initial charge and over-time change, the reduction in carbon emissions from the consumption of fossil fuels due to the three scenarios diverges over time. In particular, the reduction in global carbon emissions from the scenario of collection by flag is less than that from 
the scenario of collection by harbors of destination/origin, and both are less than that from the scenario of the benchmark scenario, and the gap is widening over time. This suggests that implementing a bunker emissions charge through collection by flag or by destination/origin tends to be less efficient than imposing the framework through a universal global framework in coping with bunker emissions.

Figure 6: Global bunker emissions by different scenarios for imposing the framework

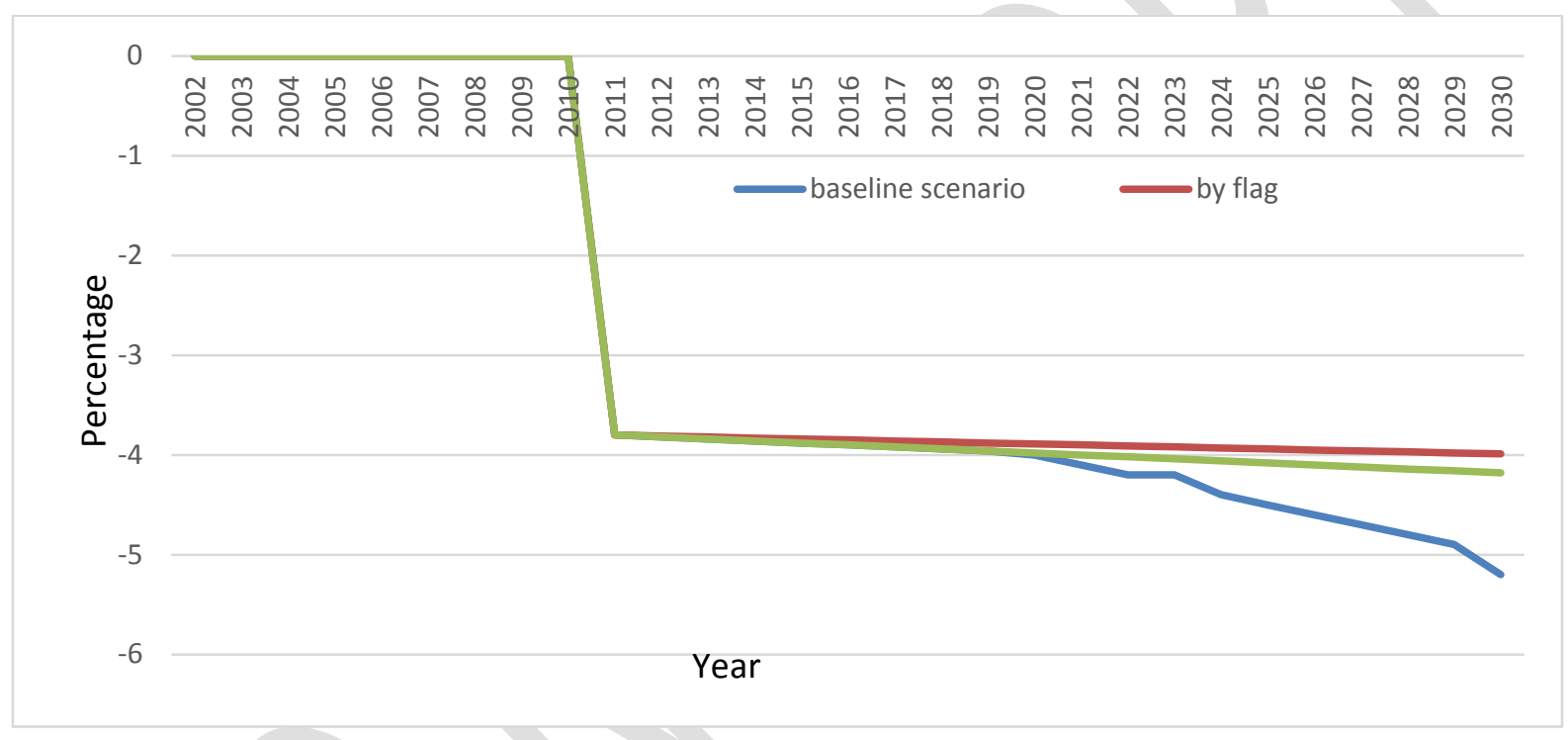

A possible explanation for this phenomenon is that: when the bunker emissions charge is implemented by flag or by the harbor of destination/origin, the regions with no or less bunker emissions charge will provide more transportation services with more consumption of bunker fuels to substitute for the international transportation services with the bunker emissions charge.

Although the reduction in bunker emissions under the two alternative scenarios is worse than the benchmark scenario, the economic costs associated with trade reduction and trade diversion 
effects become larger. As is shown in Figure 7, the average import prices of major commodities increase more quickly under the two alternative scenarios than those under the benchmark scenario. Such a change is more likely to be driven by the strong trade diversion effect, plus the reduction in the supply response effects and the technological progress effects. This is because the countries and regions which are unwilling to flag for imposing a bunker emissions charge are usually developing countries and less efficient in production and transportation of all types of commodities. A bunker emissions charge by flag or by destination/origin is comparable to taxing the relatively more efficient producers to subsidize the less efficient ones and thus cause the misallocation of resources throughout the world.

Figure 7: Response of import prices in different scenarios under a universal bunker charge

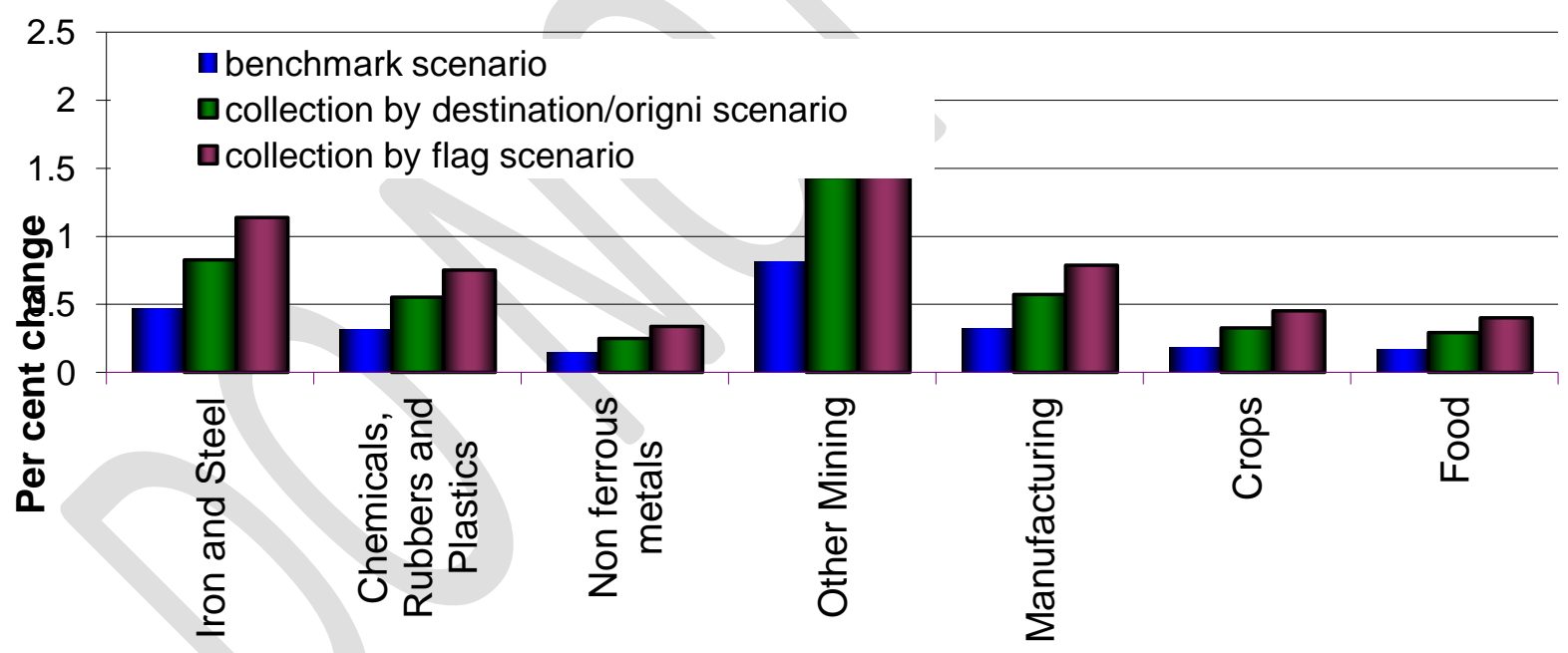

Combining the costs and benefits obtained from the two alternative scenarios and comparing them with those from the benchmark scenario suggests that imposing a universal bunker emissions charge is more beneficial to the whole world. 


\section{Pathway towards Implementing the Global Framework}

In the previous section, we discussed the economic benefits and costs related to imposing a bunker emissions charge, respectively. The bunker emissions charge was found to bring benefits by raising tax revenues and reducing the quantity of bunker emissions. It also induces costs by decreasing trade volumes and diverting trade. Yet, whether the international framework for a bunker emissions charge could be established depends on the net impact of the bunker emissions charge. This section combines the costs and benefits by looking at the change in GDP in response to the bunker emissions charge.

\subsection{The Global Bunker Emissions Charge and Net Economic Welfare Measure} Based on the baseline scenario with no bunker emissions charge, the real GDP of each region will significantly increase by 2030 but the increases are unevenly distributed across regions. The increases in real GDP and global trade are driven mainly by the endogenous growth in population and investment and the exogenously technological progress. According to our projection, China will overtake the US and become the largest economy with real GDP reaching US\$ 31.7 trillion, followed by the US (US\$22.9 trillion), EU 25 countries (US\$ 18.2 trillion), India (US\$ 7.9 trillion), Japan (US\$ 5.8 trillion) and Russia (US\$ 4.7 billion) (Table 3). At the same time, global trade will grow more quickly than real GDP but the growth rate will slow down. Due to the rise of protectionism and the substantial weakening investment in fixed investment growth both in developed and developing countries, the ratio of global trade growth to world GDP has steadily fallen from a factor of 2.5 to 1 . 
Table 3: Annual GDP growth rate by region in 2030

\begin{tabular}{lll}
\hline Country Name & $\begin{array}{l}\text { Without bunker } \\
\text { emissions charge }(\%)\end{array}$ & $\begin{array}{l}\text { With bunker emissions } \\
\text { charge }(\%)\end{array}$ \\
\hline US & 2.00 & 1.99 \\
EU 25 & 1.47 & 1.47 \\
China & 7.68 & 7.59 \\
Former Soviet Union & 3.68 & 3.51 \\
Japan & 0.79 & 0.80 \\
India & 7.43 & 7.33 \\
Canada & 1.79 & 1.77 \\
Australia & 2.76 & 2.71 \\
Indonesia & 6.01 & 5.89 \\
South Africa & 4.65 & 4.55 \\
Other Southeast Asian Countries & 4.21 & 4.19 \\
OPEC & 4.67 & 4.57 \\
Rest of World & 5.24 & 5.22 \\
\hline
\end{tabular}

Note: the estimation is made based on the assumptions of the baseline scenario.

However, when implementing a bunker emissions charge, the annual growth rates for all regions tend to decline, though the change is modest in magnitude. By 2030, implementation of a bunker emissions charge is estimated to cause each country to lose US\$5.31billion (in 2001 dollars) of gross national income. Of this amount, US\$6.52 billion is accounted for by loss of GDP with a gain of US\$ 1.21 billion from terms of trade improvement.

Figures 8 illustrates the dynamic path of real GDP for selected regions when imposing a bunker emissions charge. Such a dynamic change in GDP reflects the net impact of the emissions charge on imports, exports and domestic production from a general equilibrium perspective.

Figure 8: Real GDP under the basic scenario with a global bunker emissions charge 


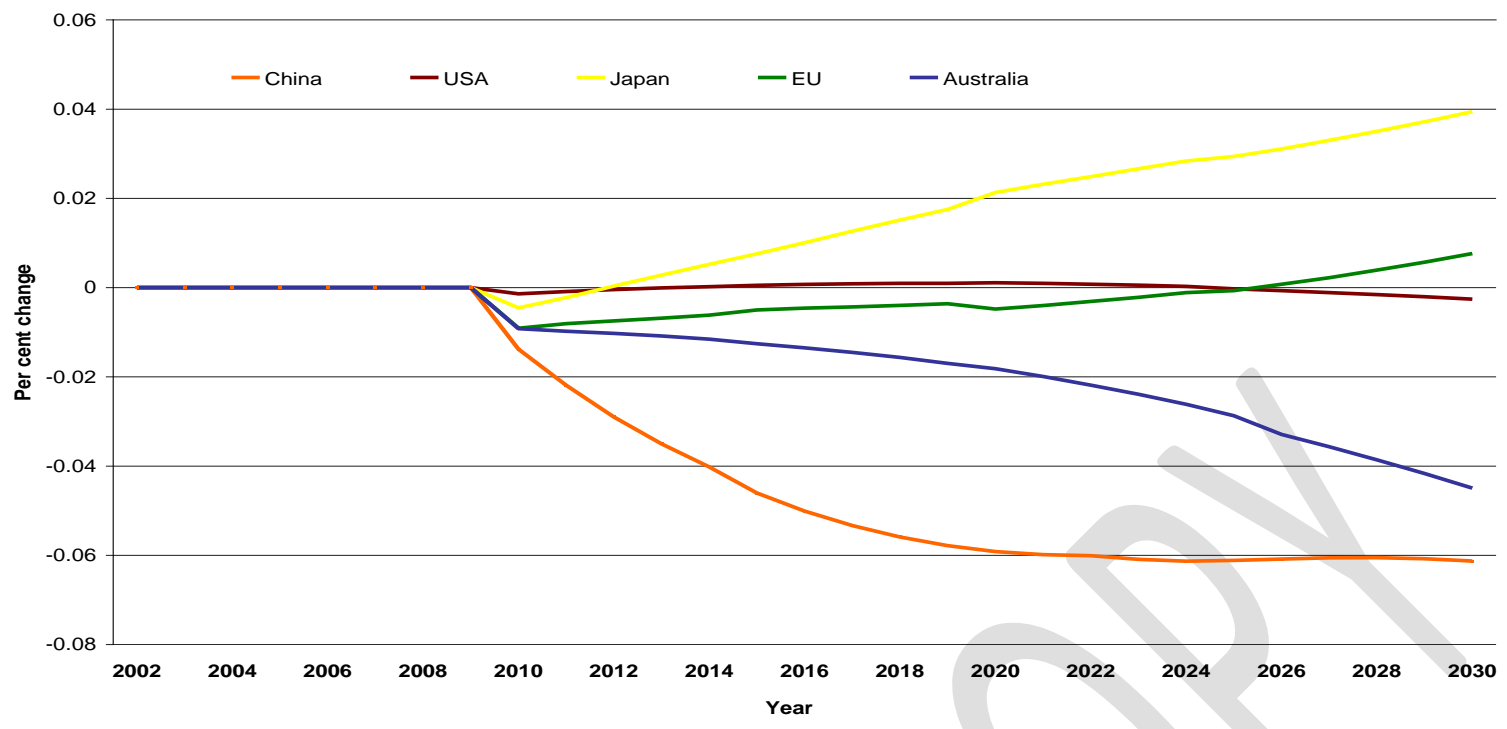

Note: the change is expressed as the change relative to the basic scenario without a bunker emissions charge.

With the implementation of a bunker emissions charge, EU 25 countries and Australia are likely to experience a slight fall in their GDP resulting from a fall in exports and increased price of imports. In addition, China is also projected to experience a slight fall in GDP. China's economy is more reliant on trade than the other countries featured in Figures 3 and 4. It imports large volumes of low value coal and iron ore, the prices of which are expected to increase. In addition, China's exports are relatively intensive in international transport services, thereby inducing a large adjustment in the Chinese economy with the imposition of bunker emissions charges.

Economies such as the United States, Japan and the European Union are estimated to experience nil to minor increases in GDP. These regions are closer to their major trade partners, and are aided by trade winds and ocean currents, meaning that the amount of bunker fuel required to transport goods to major trading partners remains low compared to countries such as Australia. 
Furthermore, these countries generally export high value-low volume goods from high-tech manufacturing. The impact of a bunker emissions charge on the prices of goods exported from the United States, Japan and the European Union is likely to be low compared with export competitors. Whether a country loses or gains in terms of real GDP, the changes are estimated to be very small.

\subsection{Revenue Redistribution Policy and Its Impact for Implementation}

It is widely believed that the way to redistribute the revenues from a bunker charge between countries and regions will affect the incentives for individual countries participating in the global framework for a bunker emissions charge. To access the impact of different redistribution policies on the welfare of each country, we designed three revenue distribution scenarios for simulation following the current policy debate in practice. These three scenarios include: (I) 'redistributing revenue according to the revenue collection', (II) 'redistributing revenues only to the developing countries according to their trade volume', and (III) "redistributing revenue to all countries and regions evenly'.

The simulation results are shown in Table 4, where column 1 provides the loss in GDP for each country and region due to a bunker emissions charge and columns 2-4 provide the gain in GDP from using different revenue redistribution policies.

Table 4: Aggregate economic effects of a global bunker emissions charge and revenue redistribution in 2030

\begin{tabular}{lllll}
\hline & Loss & Revenue & Revenue & Revenue \\
Country Name & $($ GDP \%) & Distribution I & Distribution & Distribution \\
\hline
\end{tabular}




\begin{tabular}{lllll}
\hline & & $(\mathrm{GDP} \%)$ & II (GDP \%) & III (GDP \%) \\
\hline US & -0.003 & 0.009 & - & 0.005 \\
EU 25 & 0.008 & 0.033 & - & 0.010 \\
China & -0.061 & 0.009 & 0.030 & 0.009 \\
Former Soviet Union & -0.039 & 0.008 & - & 0.038 \\
Japan & 0.039 & 0.029 & - & 0.021 \\
India & -0.091 & 0.004 & 0.067 & 0.039 \\
Canada & -0.019 & 0.004 & - & 0.070 \\
Australia & -0.045 & 0.006 & - & 0.121 \\
Indonesia & -0.140 & 0.007 & 0.079 & 0.008 \\
South Africa & -0.047 & 0.006 & 0.039 & 0.027 \\
Other Southeast Asian Countries & -0.133 & 0.036 & 0.042 & 0.022 \\
OPEC & -0.177 & 0.015 & 0.030 & 0.036 \\
Rest of World & -0.096 & 0.022 & 0.056 & 0.012 \\
\hline
\end{tabular}

Note: the estimation is based on the assumptions of the baseline scenario.

Without considering the refund in revenues from a bunker charge, the developing countries, such as China, India and Indonesia may have no economic incentives to participate in the global initiative since they may encounter greater losses in their economic growth compared to their developed counterparts. Nor is there much economic incentive for the developed countries, such as Australia and Canada, to participate into the global initiative. They, too, would face erosion in their economic growth because they have been exporting a large proportion of low-valued materials and resources with relatively high transportation costs.

However, an international transfer from developed countries yielded additional gains from a bunker charge to developing countries, thereby helping to alleviate the situation and giving all countries and regions an incentive to participate in a global bunker emissions charge

When comparing the net impacts of the three revenue redistribution policies, we have reason to believe that policy II is superior to policies I and III in facilitating the establishment of the global 
framework for a bunker emissions charge. This is because policy II gives more compensation to the developing countries, which suffer from more losses as a result of the implementation of a bunker emissions charge. In contrast, policies I and II give more or equal benefits to the developed countries, which are more likely to benefit from the implementation of a bunker emissions charge.

Even without economic benefits, the developed countries may have more political willingness to participate in a global bunkers emissions charge than the developing countries since they have put more emphasis on environmental issues than economic development.

\subsection{Beyond Economic Costs and Benefits: Long-term Competitiveness Analysis}

Although the GDP measure simplifies the cost-benefit analysis, it will not inform us about the long-term impact of imposing a bunker emissions charge. In practice, many countries care more about comparative advantage or competitiveness than GDP growth. Thus, whether the international framework for a bunker emissions charge could be established also depends on how it will alter the competitive and comparative advantage positions of trading partners throughout the world.

If a country has a comparative advantage in a commodity, it will appear prominent in the country's export commodities bundle. In other words, its share in the total value of exports will remain high. Using this method, we examine the change in shares due to the implementation of a bunker emissions charge under the baseline scenario and present the results in Table 5. This provides a simple way to examine changes in the revealed comparative advantage position of 
commodities for each country. Generally, we show that implementing a bunker emissions charge shifts the commodity distribution of comparative advantage position in all countries, but the impact is relatively small.

Table 5: Estimated change in share of commodity in total value of exports from a country/region under the basic scenario in 2030 (unit: percentage)

\begin{tabular}{llllllllllllll}
\hline & USA & EU 25 & CHN & FSU & JPN & IND & CAN & AUS & IDN & SAF & OAS & OPEC & ROW \\
\hline Coal & -0.1 & 1.5 & -0.1 & -0.5 & 0.3 & 0.8 & -0.8 & -0.4 & -0.7 & -0.4 & -0.3 & -0.2 & -0.2 \\
Gas & -0.2 & 0.1 & 0.7 & 0 & 0.4 & 1 & 0 & 0 & 2.5 & 0.4 & 1.9 & 0.3 & 0.3 \\
Iron and Steel & 0.2 & 0.1 & 0.8 & 0.4 & 0.4 & -0.5 & 0.7 & -0.1 & 0 & 0.2 & -0.1 & 0.1 & 0 \\
Non-ferrous metals & 0.1 & -0.3 & 0.5 & -0.1 & -0.3 & -0.6 & 0.1 & 0.2 & 0.7 & 0.8 & -0.6 & 0.6 & 0 \\
Chemicals, rubbers & -0.1 & 0.1 & -0.3 & 0.1 & 0 & 0 & -0.1 & 0.3 & -0.9 & -0.3 & -0.3 & -0.2 & -0.1 \\
and plastics & & & & & & & & & & & \\
Other mining & 0.1 & -0.1 & -0.6 & 0 & -0.7 & 0.3 & -0.3 & -0.5 & -0.1 & 0.1 & 0.3 & -0.2 & 0 \\
Non-metallic minerals & -0.1 & 0 & 0.2 & 0.7 & 0.2 & -1.2 & 0.8 & 1 & -0.1 & 0.3 & -0.7 & -0.6 & -0.1 \\
Manufacturing & 0.1 & -0.1 & -1 & 0 & 0 & -0.5 & -0.1 & -0.1 & -1.3 & 0.1 & -0.1 & 0.2 & 0.1 \\
Crops & 0.1 & -0.3 & -0.1 & -0.5 & -0.1 & 0.3 & -0.3 & -0.3 & 0.1 & -0.8 & 0.1 & -0.4 & 0 \\
Food & -0.3 & -0.3 & 0 & 0.1 & -0.3 & -0.3 & -0.2 & -0.4 & -0.2 & -0.5 & -0.1 & 0 & -0.3 \\
Services & 0.2 & -0.3 & -0.4 & -0.4 & 0.2 & 0.1 & -0.4 & 0.1 & 0.1 & 0.1 & 0.6 & 0.4 & 0.3 \\
\hline
\end{tabular}

To examine whether a country's competitive position would be adversely affected by the inclusion of bunker emissions in the scope of a global carbon charge, the share of each commodity in the global trade is calculated and reported for the year 2030 in Table 6 . The key point to note is that if a country remains competitive, its market share in the global value of trade in the commodity will not decline. The implication is that the impact of a bunker emissions charge on the transport cost for each commodity is not projected to be significant for the carbon charge paths modelled. Overall, the extension of a carbon charge to cover international bunker emissions is not projected to significantly alter the value of individual commodity exports in all regions. Any differences are very small. 
Table 6: Estimated change in share of various commodities in global trade of the same commodity under the basic scenario in 2030 (unit: percentage)

\begin{tabular}{lllllllllllllll}
\hline & USA & EU25 & CHN & FSU & JPN & IND & CAN & AUS & IDN & SAF & OAS & OPEC & ROW \\
\hline Coal & -0.3 & 1.5 & 0.7 & -0.5 & -0.2 & 1.2 & -0.8 & -0.2 & 0.2 & -0.6 & -0.3 & -0.3 & -0.2 \\
Gas & -1.1 & -0.6 & 0.9 & -0.8 & -0.8 & 0.7 & -0.6 & -0.5 & 2.7 & -0.5 & 1.2 & -0.5 & -0.4 \\
Iron and Steel & -0.3 & -0.1 & 1.4 & 0.1 & -0.3 & -0.4 & 0.5 & -0.1 & 0.6 & -0.3 & -0.4 & -0.3 & -0.3 \\
$\begin{array}{l}\text { Non-ferrous } \\
\text { metals }\end{array}$ & -0.3 & -0.4 & 1.3 & -0.3 & -0.9 & -0.4 & 0.1 & 0.2 & 1.5 & 0.4 & -0.8 & 0.3 & -0.2 \\
$\begin{array}{l}\text { Chemicals, } \\
\text { rubbers }\end{array}$ & -0.2 & 0.1 & 0.6 & 0.1 & -0.4 & 0.4 & 0 & 0.5 & 0 & -0.4 & -0.3 & -0.3 & -0.1 \\
and plastics & & & & & & & & & & & & & \\
Other mining & -0.1 & -0.1 & 0.3 & -0.1 & -1.2 & 0.7 & -0.2 & -0.3 & 0.8 & -0.1 & 0.3 & -0.3 & 0 \\
$\begin{array}{l}\text { Non-metallic } \\
\text { minerals }\end{array}$ & -0.5 & -0.1 & 0.9 & 0.5 & -0.4 & -1 & 0.7 & 1 & 0.7 & -0.1 & -0.9 & -0.9 & -0.3 \\
Manufacturing & 0 & 0 & 0 & 0 & -0.3 & 0 & 0 & 0.2 & -0.3 & 0 & 0 & 0.1 & 0.1 \\
Crops & 0 & -0.3 & 0.8 & -0.5 & -0.6 & 0.7 & -0.2 & 0 & 1.1 & -0.9 & 0.2 & -0.5 & 0 \\
Food & -0.4 & -0.2 & 1 & 0.1 & -0.7 & 0.1 & 0 & -0.1 & 0.8 & -0.6 & 0 & -0.1 & -0.3 \\
Services & -0.2 & -0.4 & 0.3 & -0.6 & -0.4 & 0.3 & -0.5 & 0.1 & 0.9 & -0.3 & 0.4 & 0.1 & 0.2 \\
\hline
\end{tabular}

\section{Conclusion and Policy Implications}

Under the Kyoto Protocol, bunker emissions are not included in the national inventory of GHG emissions. As a result, these emissions are excluded from the scope of carbon pricing, following any agreement on national emissions restrictions. With the rapid expansion of international trade and the associated increased consumption of bunker fuels, how to restrict bunker emissions has become an important public concern.

To date, there have been many proposals to include bunker emissions within the scope of carbon pricing, among which a global bunker emissions charge is considered as a possible way. However, it is difficult for a global climate policy framework to gain support from both developed and developing countries. As a carbon charge on bunker fuel emissions would increase economic costs through reducing trade flows and changing trade patterns, developing 
countries and the countries that are located some distance from their trading partners are legitimately concerned about the possible negative income and competitive effects. Therefore, understanding the economic impacts of a bunker emissions charge can assist different countries commit to a global deal. However, the existing literature seldom considers the general equilibrium effects and the inequalities that could result from a global bunker emissions charge.

This study employed a dynamic CGE model to quantify the economic impacts of implementing a global bunker emissions charge. The economic impacts of a global bunker emissions charge on global trade volume and trade flows, as well as the comparative production advantage and competitiveness of each country were all assessed.

We found that including bunker emissions in a standard CPRS-5 environment would have a very small impact on global trade and production. Its impact on real GDP was estimated to be less than -0.5 percent. This study also confirms that the magnitudes of any negative effects are small, since the competitive and comparative advantages of a country (particularly developing countries) are unlikely to be affected by the inclusion of bunker emissions in the carbon pricing environments. Using a transparent and simple revenue redistribution mechanism, we demonstrate that less developed countries will not be disadvantaged when the revenue distribution mechanism is properly designed.

Finally, our study informs the policy debate regarding the control of marine transport emissions. The limited economic impact of a bunker emissions charge implies that a global bunker emissions charge is economically feasible and desirable when compared to the benefits from 
emissions reduction. Designing a mechanism to redistribute revenues from the global emissions charge from developed countries to developing countries could encourage the participation of more countries. While the proposal needs some level of clarification from developed countries, it is consistent with the principle of 'Common but Differentiated Responsibility' that developed countries may shoulder more responsibility in mitigating climate change.

Our analysis aims to provide an analytical framework to support political debates. It does not make actual decisions, such as allocation of emissions, which is politically controversial and beyond the scope of this paper. The international community must build consensus through political dialogue, and also conduct further joint technical studies similar to this. 
References

Abrell J, 2000. Regulating CO2 emissions of transportation in Europe: A CGE-analysis using market-based instruments. Transportation Research Part D: Transport and Environment. 15, 235239.

Allan G, Lecca P, McGregor P, Swales K, 2014. The economic and environmental impact of a carbon tax for Scotland: A computable general equilibrium analysis. Ecological Economics 100, 40-50.

Allen Consulting Group, 2006. Deep Cuts in Greenhouse Gas Emissions: Economic, Social and Environmental Impacts for Australia. Report to the Business Roundtable on Climate Change. Alton T, Arndt C, Davies R, Hartley F, Makrelov K, Thurlow J, Ubogu D, 2014. .Introducing carbon taxes in South Africa. Applied Energy. 116, 344-354.

Araar A, Dissou Y, Duclos J, 2011. Household incidence of pollution control policies: A robust welfare analysis using general equilibrium effects. Journal of Environmental Economics and Management. 61, 227-243.

Australian Government, 2008. Carbon Pollution Reduction Scheme Green Paper. Australian Government, Canberra.

Böhringer C, Rutherford T, 1997. Carbon taxes with exemptions in an open economy: A general equilibrium analysis of the German tax initiative. Journal of Environmental Economics and Management 32, 189-203.

C B, Kelly DL, 2012. Trade and the environment with pre-existing subsidies: A dynamic general equilibrium analysis. Journal of Environmental Economics and Management. 64, 253-278.

Carbone J, Kerry SV, 2013. Valuing nature in a general equilibrium. Journal of Environmental Economics and Management. 66, 72-89.

Cariou P, Cheaitou A, 2012. The effectiveness of a European speed limit versus an international bunker-levy to reduce CO2 emissions from container shipping. Transportation Research Part D: Transport and Environment. 17, 116-123.

Commonwealth of Australia, 2008. Australia's Low Pollution Future: The Economics of Climate Change Mitigation, ACT: Commonwealth of Australia.

CSIRO, 2008. Modelling of the Future of Transport Fuels in Australia: A report to the Future Fuels Forum, Newcastle: CSIRO Energy Transformed.

European Parliament, 2015. Emission Reduction Targets for International Aviation and Shipping, European Union, Brussels.

European Parliament, Council of the European Union, 2015. Regulation (EU) 2015/757 of the European Parliament and of the Council of 29 April 2015 on the monitoring, reporting and verification of carbon dioxide emissions from maritime transport, and amending Directive 2009/16/EC (Text with EEA relevance). European Parliament.

Franc P, Sutto L, 2014. Impact analysis on shipping lines and European ports of a cap- and-trade system on CO2 emissions in maritime transport. Maritime Policy \& Management 41, 61-78.

Garnaut R, 2008. Garnaut Climate Change Review Final Report. Cambridge University Press, Melbourne.

Gilbert P, Bows A, 2012. Exploring the scope for complementary sub-global policy to mitigate CO2 from shipping. Energy Policy. 50, 613-622. 
Goulder L, 1995. Effects of carbon taxes in an economy with prior tax distortions: An intertemporal general equilibrium analysis. Journal of Environmental Economics and Management. 29, 271-297.

ICS, 2014. Shipping, World Trade and the Reduction of $\mathrm{CO}_{2}$ Emissions. International Chamber of Shipping (ICS) London.

IEA, 2009. CO2 Emissions From Fuel Combustion Highlights 2009. International Energy Agency, Paris.

IMF, 2016. After Paris: Fiscal, Macroeconomic, and Financial Implications of Climate Change, I M F Staff Discussion Note, Washington D.C.

IMO, 2009a. Report of the Marine Environment Protection Committee on its Fifty-ninth Session. International Maritime Organization.

IMO, 2009b. Second IMO GHG Study 2009. International Maritime Organization, London.

IMO, 2014. Report of the third Intersessional Meeting of the working group on greenhouse gas emissions from ships. International Maritime Organization.

IMO, 2017. Our Work--Air Pollution and GHG Emissions

http://www.imo.org/en/OurWork/Environment/PollutionPrevention/AirPollution/Pages/Default.a spx (Accessed 24 April 2017).

Lee T, Chang Y, Lee P, 2013. Economy-wide impact analysis of a carbon tax on international container shipping. Transportation Research Part A 58, 87-102.

Lee T, Lam JSL, Lee P, 2016. Asian economic integration and maritime CO2 emissions.

Transportation Research Part D: Transport and Environment. 43.

Miola A, Marra M, Ciuffo B, 2011. Designing a climate change policy for the international maritime transport sector: Market-based measures and technological options for global and regional policy actions. Energy Policy. 39, 5490-5498.

Monkelbaan J, 2010. Shipping emissions: Negotiating bunker fuels in Cancun. BIORES. 4. Pant H, 2007. GTEM: Global Trade and Environment Model, ABARE Technical Report. Psaraftis HN, 2012. Market-based measures for greenhouse gas emissions from ships: a review. WMU Journal of Maritime Affairs. 11, 211-232.

Psaraftis HN, Kontovas CA, 2010. Balancing the economic and environmental performance of maritime transportation. Transportation Research Part D: Transport and Environment. 15, 458462.

Shi Y, 2016. Reducing greenhouse gas emissions from international shipping: Is it time to consider market-based measures? Marine Policy. 64, 123-134.

Sue Wing I, 2009. Computable general equilibrium models for the analysis of energy and climate policies, International Handbook on the Economics of Energy. Elgar; 2009. pp. 332-366.

UNFCCC, 1998. Kyoto Protocol to the United Nations Framework Convention on Climate Change. http://unfccc.int/kyoto_protocol/items/2830.php (Accessed 28 March 2017).

UNFCCC, 2015. Greenhouse inventory data by country - detailed data by party.

http://unfccc.int/di/DetailedByParty.do (Accessed 4 May 2018).

Wang H, 2010. Economic costs of CO2 emissions reduction for non-Annex I countries in international shipping. Energy for Sustainable Development. 14, 280-286.

Y L, Lu Y, 2015. The Economic impact of different carbon tax revenue recycling schemes in China: A model-based scenario analysis. Applied Energy 141, 96-105. 


\section{Appendix: Dynamic Path for Implementing the Global Framework}

Two important areas of uncertainty related to the implementation of a bunker emissions charge are analyzed in this appendix: marine fuel price uncertainty and carbon charge uncertainty. Each of the sensitivity analyses results is presented, only for simplicity, for real GDP and real GNP.

The central carbon charge scenario with and without imposing carbon levies on bunker emissions was conducted by altering the assumptions regarding the projected changes in marine fuel prices. The central scenario used price projection for reference. The global impact on real GNP and GDP when extending a carbon charge to bunker emissions under a higher fuel price path is presented in Table A1. There is little difference in the macroeconomic impacts of a bunker charge under the alternative marine fuel price assumptions. This aligns to expectations that fuel price assumptions are built into all carbon charge scenarios with or without a bunker charge. Hence, the impact of different bunker charge decisions is mostly negligible. For this reason, other commodity specific results are not presented.

Table B1: Estimated global macroeconomic effects in 2030 of a bunker charge under CPRS-5 scenario with alternative marine fuel price assumptions (unit: percentage)

\begin{tabular}{lll}
\hline & Central price path (\%) & High price path (\%) \\
\hline Real GDP & -0.04 & -0.05 \\
Real GNP & -0.19 & -0.20 \\
\hline
\end{tabular}

The results were replicated under two additional carbon charge paths, each with and without a bunker charge. The first of the supplementary carbon charge paths commences 45 percent below and the second commences at 40 percent above the starting carbon charge consistent with the CPRS -5 scenario. Both carbon charge paths increase at the same rate as the CPRS -5 carbon charge rises. Some key macroeconomic results under these scenarios are compared in Table A2. The results are shown relative to the equivalent carbon charge scenario, without a bunker fuel charge.

Table B2: Estimated macroeconomic effects of a global bunker fuel charge in 2030 sensitivity to the carbon charge path (unit: percentage)

\begin{tabular}{llll}
\hline & $\begin{array}{l}\text { Low carbon charge path } \\
(\%)\end{array}$ & $\begin{array}{l}\text { Central carbon charge path } \\
(\text { CPRS-5) }(\%)\end{array}$ & $\begin{array}{l}\text { High carbon charge path } \\
(\%)\end{array}$ \\
\hline Global Real GDP & -0.023 & -0.045 & -0.058 \\
Global Real GNP & -0.102 & -0.186 & -0.250 \\
\hline
\end{tabular}

The results in Table A2 suggest that the implementation of a bunker charge under higher carbon charge paths results in a larger fall in global real GDP and real GNP. The fall in the real GNP is much more pronounced than the fall in real GDP, mainly because GNP takes into account the terms of trade losses and income transfers associated with a bunker charge. 

Click here to download Simulation Code and Data (.ZIP): all_results_paper.rar

Simulation Code and Data (.ZIP)
Click here to download Simulatio Click here to download Simulation Code and Data (.ZIP): all_results_paper.rar

Code and Data (.ZIP): all_results_paper.rar (a) (1) $\sqrt{3}$ (1) (1) (1) .

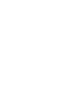

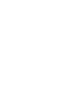
.

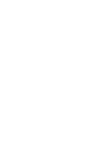

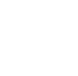

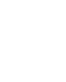

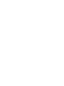

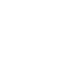

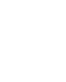

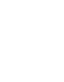

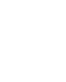

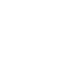

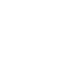

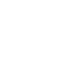

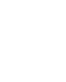

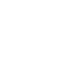

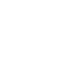

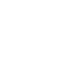

